ISLAMIC BANKING Volume 5 Nomor 2 Edisi Februari $2020 \mid \mathbf{1}$

\title{
PERAN MODERASI DISIPLIN KERJA PADA PENGARUH KEPEMIMPINAN TERHADAP PRODUKTIVITAS KERJA KARYAWAN PERBANKAN SYARIAH DI MAKASSAR
}

\author{
Edy Jumady \\ Program Studi Manajemen, STIEM Bongaya Makassar \\ Email: edy.jumady@stiem-bongaya.ac.id
}

\begin{abstract}
This study aims to examine the influence of leadership on employees work activity moderated work discipline at Islamic banking in Makassar. Data collection uses the primary data obtained from questionnaires using technitk proportionated random sampling. The population is all 162 permanent employees from 11 Islamic banks in Makassar City, while the sample taken is 62 respondents. The results of the questionnaire have been tested for validity and reliability. Methoddata analysis using SEM technique (Sturctural equation modeling) assisted with WarphPLS Ver.5.0. The results of this study indicate that the hypothesis of leadership is accepted in part because it shows the result of hypothesis test that negative and significant. This means that influential negative leadership and significant to employees work activity. then result research on work discipline shows that the hypothesis is accepted because it shows results a positive and significant hypothesis. this means that positive discipline work is positive and significant to employees work activity. While the results of research on discipline work as the strengthening variable indicates that the hypothesis is accepted as it shows the results a positive and significant hypothesis. This means that the work discipline variable can strengthen variable leadership on employees work activity.
\end{abstract}

Keywords: Leadership, Work Discipline, Employee Performance, Islamic Banking

\section{Dasar Pemikiran}

Dalam perkembagan bisnis perbankan syariah sangat pesat saat ini. Hal ini dapat dilihat dari banyaknya perbankan syariah yang beroperasi di tahun 2019 yang bermunculan untuk menarik minat nasabah yang awalnya menyimpan dananya di bank konvensional beralih ke bank syariah, sehinggan persaingan dalam bisnis syariah semakin ketat, hal tersebut mengakibatkn harus memperhatikan sumber daya manusia yang dimilikinya. Karyawan dituntut untuk menghasilkan kinerja yang tinggi. Otoritas Jasa Keuangan (OJK) Regional 6 Sulawesi, Maluku dan Papua (Sulampua) mencatat, pembiayaan Bank Syariah tahun 2019 di Sulawesi Selatan masih tumbuh (Tribun Timur, 2019) 


\section{2 | Edy Jumady, PERAN MODERASI DISIPLIN KERJA PADA PENGARUH KEPEMIMPINAN.}

Berdasarkan latar belakang yang telah diuraikan, maka tujuan penelitian ini adalah untuk mengetahui peran moderator disiplin kerja pada pengaruh kepemimpinan terhadap produktivitas kerja karyawan. Kepemiminan adalah kemampuan untuk mempengaruhi sesuatu kelompok menuju tercapainya tujuan-tujuan (Robbin dan Coulter, dalam Widodo, 2010). Kepemimpinan adalah aktivitas mempengaruhi orangorang supaya diarahkan mencapai tujuan organisasi (Thoha dalam Mondiani, 2012).

Gaya Kepemimpinan merupakan cara pimpinan untuk mempengaruhi orang lain/bawahannya sedemiian rupa sehingga mau melakukan kehendak pimpinan untuk mencapai tujuan organisasi meskipun secara pribadi hal tersebut mungkin tidak disenangi (Luthans, 2011). Terdapat tiga jenis perilaku kepemimpinan yang saling berbeda diantara para manejer, yaitu: perilaku berorientasi pada tugas (task oriented behavior), perilaku berorientasi pada hubungan (relationship oriented behavior),dan kepemimpinan partisipatif (P. Siagian, 2002). Berdasarkan pengertian Kepemimpinan yang telah dikemukakan, maka dapat disimpulkan Kepemimpinan adalah kemampuan untuk mempengaruhi baik itu individu maupun sekelompok orang untuk mencapai tujuan organisasi maupun perusahaan.

Berdasarkan penelitian terdahulu yang dikemukan oleh (T. Widodo, 2010) menyatakan bahwa kepemimpinan berpengaruh positif signifikan terhadap produktivitas karyawan kecamatan Sidorejo Kota salatiga. Temuan ini dibantahkan oleh (Posuma, 2013) bahwa Kepemimpinan tidak berpengaruh terhadap produktivitas karyawan pada Rumah Sakit Ratumbuysang Manado. Fakta lapang mengenai kepemimpinan menunjukkan bahwa kurangnya kemampuan pemimpin untuk memberitahu bawahan apa yang harus dia kerjakan dan kurangnya kemampuan menjual, memberi ide dan berpartisipasi dengan anggotanya.

H1 : Kepemimpinan berpengaruh positif terhadap produktivitas kerja karyawan perbankan syariah di Makassar

Selain kepemimpinan yang mempunyai pengaruh terhadap produktivitas kerja karyawan, disiplin kerja merupakan faktor yang mempengaruhi produktivitas kerja karyawan. Disiplin kerja adalah sikap, tingkah laku dan perbuatan sesuai dengan peraturan dari organisasi baik itu tertulis maupun tidak tertulis (Nitisemito, 2014). 
Disiplin kesadaran dan kesediaan seseorang menaati semua peraturan perusahaan dan norma-norma sosial yang berlaku (Abdillah \& Wajdi, 2011). Disiplin kerja adalah suatu proses yang dapat menumbuhkan perasaan seseorang untuk mempertahankandan meningkatkan tujuan organisasi secara obyektif, melalui kepatuhannya menjalankan peraturan organisasi (Prawatya \& Raharjo, 2012).

Berdasarkan penelitian terdahulu yang dikemukan oleh (Prawatya \& Raharjo, 2012) bahwa Disiplin kerja berpengaruh positif signifikan terhadap kinerja karyawan pada Pabrik Minyak Kayu Putih (PMKP) di Krai Porwodadi. Temuan ini dibantah oleh (Susanty \& Baskoro, 2016) bahwa disiplin kerja tidak berpengaruh terhadap kinerja pegawai.

H2 : disiplin kerja berpengaruh positif terhadap produktivitas kerja karyawan perbankan syariah di Makassar

Fakta lapang mengenai disiplin kerja menunjukkan bahwa masih banyaknya karyawan yang datang terlambat dan menggunakan waktu istirahat mereka yang tidak sesuai dengan peraturan atau prosedur kerja didalam perusahaan. Selain itu ada pegawai yang tidak hadir dalam bekerja tanpa alasan dan masih banyaknya tugas yang tidak dilaksanakan sesuai dengan prosedur. Variabel moderasi merupakan variabel yang bersifat memperkuat atau memperlemah variabel penjelas terhadap variabel tergantung.

H3 : Kepemimpinan berpengaruh positif dan signifikan terhadap produktivitas kerja karyawan di moderasi disiplin kerja pada perbankan syariah di Makassar

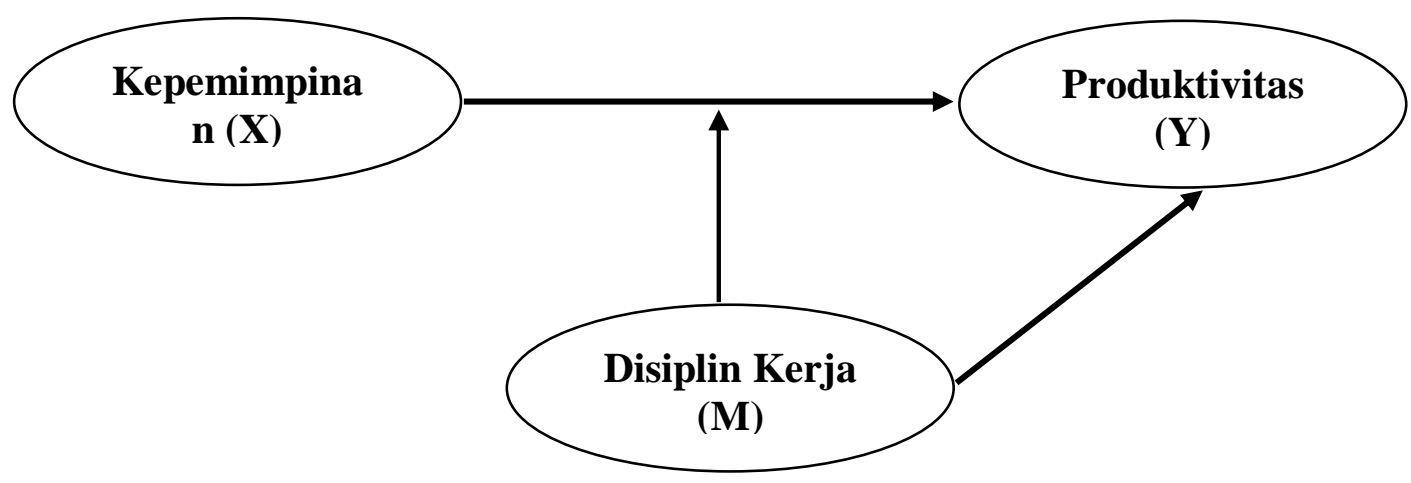

Gambar 1. Kerangka Konseptual Penelitian 


\section{Metode Penelitian}

Penelitian ini berpendekatan kuantitatif, berjenis asosiatif. Data yang di peroleh dalam penelitian ini akan diolah dan dianalisis serta di dukung dengan teori agar dapat membuktikan hipotesis dan menjawab rumusan masalah rumusan masalah yang sudah dibuat sebelumnya. Penelitian ini dilakukan pada perbankan syariah di Makassar. Pemilihan lokasi penelitian ini didasarkan adanya pertimbangan penerapan kepemimpinan, disiplin kerja dan kinerja karyawan serta tersedianya data yang diperlukan dalam penelitian ini.

Tabel 1. Operasionalisasi Variabel

\begin{tabular}{|c|c|c|}
\hline Variabel & Defenisi & Indikator Variabel \\
\hline $\begin{array}{l}\text { Kepemimpinan } \\
\text { (Riyadi, 2011) }\end{array}$ & $\begin{array}{l}\text { Tanggapan responden } \\
\text { terhadap gaya dan perilaku } \\
\text { Meneger untuk mengikuti } \\
\text { apa yang dikehendakinya }\end{array}$ & $\begin{array}{l}\text { 1) Berorientasi Hasil } \\
\text { 2) Mampu } \\
\text { Memberikan Ide } \\
\text { 3) Berpartisipasi } \\
\text { Dengan Anggota } \\
\text { 4) Mampu } \\
\text { Mengarahkan } \\
\text { Bawahan }\end{array}$ \\
\hline $\begin{array}{l}\text { Disiplin Kerja } \\
\text { Sentono dalam (Erisna, } \\
\text { 2012) }\end{array}$ & $\begin{array}{l}\text { Tanggapan } \\
\text { terhadap sesponden } \\
\text { mental yang dengan } \\
\text { kesadaran dan keinsyafan } \\
\text { mematuhi } \\
\text { perintah, larangan - } \\
\text { larangan terhadap suatu hal } \\
\text { karena mengerti baik dan } \\
\text { buruk tentang perintah dan } \\
\text { larangan. }\end{array}$ & $\begin{array}{l}\text { 1) Tingkat Kehadiran } \\
\text { 2) Kepatuhan } \\
\text { 3) Pelaksanaan Tugas } \\
\text { 4) Sanksi } \\
\text { 5) Wewenang dan } \\
\text { Tanggung Jawab }\end{array}$ \\
\hline $\begin{array}{l}\text { Produktivitas } \quad \text { Kerja } \\
\text { Karyawan } \\
\text { (Sedarmayanti, 2009) }\end{array}$ & $\begin{array}{lr}\text { tanggapan } & \text { responden } \\
\text { terhadap hasil kerja secara } \\
\text { kualitas dan kuantitas yang } \\
\text { dicapai oleh } & \text { seorang } \\
\text { karyawan } & \text { dalam } \\
\text { melaksanakan } & \text { tugasnya } \\
\text { sesuai dengan } & \text { tanggung } \\
\text { jawab yang } & \text { diberikan } \\
\text { kepadanya. } & \end{array}$ & $\begin{array}{l}\text { 1) Kuantitas Kerja } \\
\text { 2) Kualitas Kerja } \\
\text { 3) Kreativitas Kerja } \\
\text { 4) Pengetahuan } \\
\text { Pekerjaan }\end{array}$ \\
\hline
\end{tabular}

Sumber: Konsep yang dikembangkan dalam penelitian ini, 2019 
Populasi dalam penelitian adalah seluruh karyawan tetap yang bekerja pada perbankan syariah di Makassar yang berjumlah 162 orang Karyawan. Teknik pengambilan sampel dalam penelitian ini menggunakan rumus Slovin yaitu:

$$
\mathrm{n}=\frac{\mathrm{N}}{1+\mathrm{N}(\mathrm{e})^{2}}
$$

dimana:

$\mathrm{n}$ = Jumlah sampel

$\mathrm{N}=$ Jumlah populasi

$\mathrm{e}=$ Persentase kelonggaran ketidaktelitian (presisi) karena kesalahan pengambilan sampel yang masih dapat ditolerir atau diinginkan $=10 \%$ dengan perhitungan sebagai berikut :

$$
\begin{aligned}
n & =\frac{162}{1+162(0,1)^{2}} \\
& =62 \text { sampel }
\end{aligned}
$$

Teknik pengambilan sampel dilakukan dengan menggunakan sampel acak berstrata/ berkelompok (proportionated random sampling). Analisis penelitian ini menggunakan pendekatan moderation regression analysis dengan bantuan alat SEMPLS, analisis ini menggunakan pendekatan analitik yang fungsinya untuk mempertahankan integritasi sample dan memberikan dasar untuk mengontrol pengaruh variabel moderator (Ghozali, 2013). Moderator regression analysis dalam penelitian ini memiliki tiga persamaan sebagai berikut:

$$
\begin{aligned}
& \mathrm{Y}=\mathrm{a}+\mathrm{b}_{1} \mathrm{X} \\
& \mathrm{Y}=\mathrm{a}+\mathrm{b}_{2} \mathrm{M} \ldots \ldots \ldots \ldots \ldots \ldots \ldots \ldots \ldots \ldots \ldots \ldots \ldots \ldots
\end{aligned}
$$

\section{Pembahasan}

Pada uji model WarpPls, kesesuaian model diukur dengan nilai Average path coefficient (APC), Average $R$-squared (ARS), dan Average adjusted $R$-squared (AARS) serta Average block VIF (AVIF), untuk itu hasilnya ditunjukkan pada Tabel berikut:

Tabel 2

Pengujian Model

\begin{tabular}{lll}
\hline Pengukuran & & Nilai \\
\hline Average path coefficient (APC) & 0.294 & $\mathrm{P}=0.003$ \\
Average R-squared (ARS) & 0.517 & $\mathrm{P}<0.001$ \\
Average adjusted R-squared (AARS) & 0.492 & $\mathrm{P}<0.001$ \\
\hline P-ISSN : 2460-9595 & & E-ISSN : 2686-5149
\end{tabular}




\section{6 | Edy Jumady, PERAN MODERASI DISIPLIN KERJA PADA PENGARUH KEPEMIMPINAN.}

\begin{tabular}{lll}
\hline Average block VIF (AVIF) & 1.359 & acceptable if $<=5$ \\
Average full collinearity VIF (AFVIF) & 1.693 & acceptable if $<=5$
\end{tabular}

Sumber : Kuesioner penelitian (data diolah, 2019)

Langkah selanjutnya yaitu evaluasi outer model dilakukan melalui 3 kriteria yaitu convergent validity, discriminant validity dan composite reliability. Berikut ini adalah hasil pengolahan data:

\section{a. Convergent Validity (Validitas Konvergen)}

Convergent validity dari model pengukuran dapat dilihat dari korelasi antara skor indikator dengan skor konstruknya (loading factor) dengan kriteria nilai loading factor dari setiap indikator lebih besar dari 0,70 dapat dikatakan valid. Selanjutnya untuk nilai p-value apabila $<0,05$ dianggap signifikan.

Hasil pengolahan Convergent Validity dapat dilihat pada tabel berikut ini:

Tabel 3

Hasil output combined loadings and cross-loading (MODEL 1)

\begin{tabular}{|c|c|c|c|c|c|c|c|}
\hline \multicolumn{8}{|c|}{ Combined loadings and cross-loadings } \\
\hline $\begin{array}{l}\text { MODEL } \\
1\end{array}$ & KP & DSP & KNR & $\begin{array}{l}\mathrm{DSP} * \mathrm{~K} \\
\mathrm{P}\end{array}$ & $\begin{array}{l}\text { Type } \\
\text { (a }\end{array}$ & $\begin{array}{l}\mathrm{P} \\
\text { value }\end{array}$ & KETERANGAN \\
\hline $\mathrm{X} 11$ & 0.356 & 0.486 & 0.398 & 0.339 & Reflect & 0.001 & $\begin{array}{l}\text { Tidak Memenuhi convergent } \\
\text { validity }\end{array}$ \\
\hline $\mathrm{X} 12$ & 0.836 & 0.026 & 0.093 & -0.059 & Reflect & $<0.001$ & Memenuhi convergent validity \\
\hline $\mathrm{X} 13$ & 0.891 & 0.093 & 0.078 & 0.004 & Reflect & $<0.001$ & Memenuhi convergent validity \\
\hline $\mathrm{X} 14$ & 0.781 & 0.144 & 0.171 & -0.096 & Reflect & $<0.001$ & Memenuhi convergent validity \\
\hline $\mathrm{X} 21$ & $0.061^{-}$ & 0.687 & 0.308 & 0.263 & Reflect & $<0.001$ & Memenuhi convergent validity \\
\hline $\mathrm{X} 22$ & 0.023 & 0.959 & 0.055 & -0.062 & Reflect & $<0.001$ & Memenuhi convergent validity \\
\hline $\mathrm{X} 23$ & 0.06 & 0.913 & 0.144 & -0.113 & Reflect & $<0.001$ & Memenuhi convergent validity \\
\hline $\mathrm{X} 24$ & 0.076 & 0.121 & 0.226 & -0.145 & Reflect & 0.161 & $\begin{array}{l}\text { Tidak Memenuhi convergent } \\
\text { validity }\end{array}$ \\
\hline Y11 & 0.087 & 0.003 & 0.911 & 0.101 & Reflect & $<0.001$ & Memenuhi convergent validity \\
\hline Y12 & 0.115 & 0.086 & 0.865 & -0.129 & Reflect & $<0.001$ & Memenuhi convergent validity \\
\hline Y13 & 0.067 & 0.107 & 0.776 & 0.083 & Reflect & $<0.001$ & Memenuhi convergent validity \\
\hline Y14 & 0.037 & 0.186 & 0.866 & -0.052 & Reflect & $<0.001$ & Memenuhi convergent validity \\
\hline $\mathrm{X} 21 * \mathrm{X} 11$ & 0.215 & 0.502 & 0.919 & 0.289 & Reflect & 0.007 & $\begin{array}{l}\text { Tidak Memenuhi convergent } \\
\text { validity }\end{array}$ \\
\hline $\mathrm{X} 21 * \mathrm{X} 12$ & 0.284 & 0.034 & -0.22 & 0.685 & Reflect & $<0.001$ & Memenuhi convergent validity \\
\hline $\mathrm{X} 21 * \mathrm{X} 13$ & 0.114 & 0.111 & 0.525 & 0.465 & Reflect & $<0.001$ & Memenuhi convergent validity \\
\hline
\end{tabular}

P-ISSN : 2460-9595

E-ISSN : 2686-5149

DOI. 10.36908/isbank 
ISLAMIC BANKING Volume 5 Nomor 2 Edisi Februari $2020 \mid 7$

\begin{tabular}{|c|c|c|c|c|c|c|c|}
\hline $\mathrm{X} 21 * \mathrm{X} 14$ & 0.077 & 0.12 & 0.154 & 0.822 & Reflect & $<0.001$ & Memenuhi convergent validity \\
\hline $\mathrm{X} 22 * \mathrm{X} 11$ & 0.166 & 0.811 & 0.933 & 0.037 & Reflect & 0.386 & $\begin{array}{l}\text { Tidak Memenuhi convergent } \\
\text { validity }\end{array}$ \\
\hline $\mathrm{X} 22 * \mathrm{X} 12$ & 0.042 & 0.061 & 0.45 & 0.831 & Reflect & $<0.001$ & Memenuhi convergent validity \\
\hline $\mathrm{X} 22 * \mathrm{X} 13$ & 0.288 & 0.196 & 0.002 & 0.735 & Reflect & $<0.001$ & Memenuhi convergent validity \\
\hline $\mathrm{X} 22 * \mathrm{X} 14$ & 0.178 & 0.001 & 0.145 & 0.897 & Reflect & $<0.001$ & Memenuhi convergent validity \\
\hline $\mathrm{X} 23 * \mathrm{X} 11$ & 0.258 & 0.767 & 0.662 & 0.127 & Reflect & 0.15 & $\begin{array}{l}\text { Tidak Memenuhi convergent } \\
\text { validity }\end{array}$ \\
\hline $\mathrm{X} 23 * \mathrm{X} 12$ & 0.114 & 0.014 & 0.448 & 0.841 & Reflect & $<0.001$ & Memenuhi convergent validity \\
\hline $\mathrm{X} 23 * \mathrm{X} 13$ & 0.336 & 0.196 & 0.058 & 0.659 & Reflect & $<0.001$ & Memenuhi convergent validity \\
\hline $\mathrm{X} 23 * \mathrm{X} 14$ & 0.213 & 0.064 & 0.034 & 0.907 & Reflect & $<0.001$ & Memenuhi convergent validity \\
\hline $\mathrm{X} 24 * \mathrm{X} 11$ & 0.23 & 0.042 & 0.096 & 0.264 & Reflect & 0.013 & Memenuhi convergent validity \\
\hline $\mathrm{X} 24 * \mathrm{X} 12$ & 0.024 & 0.139 & 0.246 & 0.165 & Reflect & 0.086 & Memenuhi convergent validity \\
\hline $\mathrm{X} 24 * \mathrm{X} 13$ & 0.058 & 0.151 & 0.246 & 0.025 & Reflect & 0.421 & Memenuhi convergent validity \\
\hline $\mathrm{X} 24 * \mathrm{X} 14$ & 0.057 & 0.055 & $0.094^{-}$ & 0.231 & Reflect & 0.027 & Memenuhi convergent validity \\
\hline
\end{tabular}

Sumber : Kuesioner penelitian (data diolah, 2019)

Berdasarkan hasil pengolahan data diatas maka dapat dijelaskan sebagai berikut : Pada model 1 diatas, dijelaskan bahwa terdapat 2 indikator yang tidak memenuhi standart Convergent validity yaitu $\mathrm{X}_{11}$ dan $\mathrm{X}_{24}<0.70$, sehingga indicator tersebut harus dikeluarkan dari model.

Tabel 4.4

Hasil output combined loadings and cross-loading (Model 2)

\begin{tabular}{|l|r|l|l|r|r|l|l|}
\hline MODEL2 & \multicolumn{1}{l|}{ KP } & \multicolumn{1}{c|}{ DSK } & \multicolumn{1}{c|}{ KNK } & DSK*KP & Type (a & P value & Keterangan \\
\hline $\mathbf{X}_{\mathbf{1 2}}$ & 0.841 & -0.141 & -0.031 & 0.018 & 0.095 & $<0.001$ & Memenuhi convergent validity \\
\hline $\mathbf{X}_{\mathbf{1 3}}$ & 0.9 & 0.028 & 0.111 & 0.08 & 0.093 & $<0.001$ & Memenuhi convergent validity \\
\hline $\mathbf{X}_{\mathbf{1 4}}$ & 0.8 & 0.116 & -0.092 & -0.109 & 0.096 & $<0.001$ & Memenuhi convergent validity \\
\hline $\mathbf{X}_{\mathbf{2 1}}$ & -0.072 & 0.698 & -0.437 & 0.272 & 0.1 & $<0.001$ & Memenuhi convergent validity \\
\hline $\mathbf{X}_{\mathbf{2 2}}$ & -0.005 & 0.962 & 0.072 & -0.06 & 0.091 & $<0.001$ & Memenuhi convergent validity \\
\hline $\mathbf{X}_{\mathbf{2 3}}$ & 0.061 & 0.905 & 0.261 & -0.146 & 0.093 & $<0.001$ & Memenuhi convergent validity \\
\hline $\mathbf{Y}_{\mathbf{1 1}}$ & 0.087 & 0.021 & 0.911 & 0.115 & 0.093 & $<0.001$ & Memenuhi convergent validity \\
\hline $\mathbf{Y}_{\mathbf{1 2}}$ & -0.105 & 0.093 & 0.865 & -0.113 & 0.094 & $<0.001$ & Memenuhi convergent validity \\
\hline $\mathbf{Y}_{\mathbf{1 3}}$ & 0.072 & 0.086 & 0.776 & 0.057 & 0.097 & $<0.001$ & Memenuhi convergent validity \\
\hline $\mathbf{Y}_{\mathbf{1 4}}$ & -0.05 & -0.192 & 0.866 & -0.058 & 0.094 & $<0.001$ & Memenuhi convergent validity \\
\hline
\end{tabular}

P-ISSN : 2460-9595

E-ISSN : 2686-5149

DOI. https://doi.org/10.36908/isbank.v5i2.110 


\begin{tabular}{|l|r|r|r|r|r|r|l|}
$\mathbf{X}_{\mathbf{2 1}} * \mathbf{X}_{\mathbf{1 2}}$ & -0.323 & 0.108 & -0.389 & 0.678 & 0.1 & $<0.001$ & Memenuhi convergent validity \\
\hline $\mathbf{X}_{\mathbf{2 1}} * \mathbf{X}_{\mathbf{1 3}}$ & -0.167 & 0.043 & -0.763 & 0.462 & 0.108 & $<0.001$ & Memenuhi convergent validity \\
\hline $\mathbf{X}_{\mathbf{2 1}} * \mathbf{X}_{\mathbf{1 4}}$ & -0.108 & 0.169 & -0.216 & 0.806 & 0.096 & $<0.001$ & Memenuhi convergent validity \\
\hline $\mathbf{X}_{\mathbf{2 2}} * \mathbf{X}_{\mathbf{1 2}}$ & 0.017 & 0.081 & 0.406 & 0.862 & 0.094 & $<0.001$ & Memenuhi convergent validity \\
\hline $\mathbf{X}_{\mathbf{2 2}} * \mathbf{X}_{\mathbf{1 3}}$ & 0.356 & -0.238 & -0.045 & 0.759 & 0.098 & $<0.001$ & Memenuhi convergent validity \\
\hline $\mathbf{X}_{\mathbf{2 2}} * \mathbf{X}_{\mathbf{1 4}}$ & -0.14 & 0.067 & 0.069 & 0.914 & 0.093 & $<0.001$ & Memenuhi convergent validity \\
\hline $\mathbf{X}_{\mathbf{2 3}} * \mathbf{X}_{\mathbf{1 2}}$ & 0.152 & -0.018 & 0.478 & 0.856 & 0.095 & $<0.001$ & Memenuhi convergent validity \\
\hline $\mathbf{X}_{\mathbf{2 3}} * \mathbf{X}_{\mathbf{1 3}}$ & 0.398 & -0.26 & 0.021 & 0.678 & 0.1 & $<0.001$ & Memenuhi convergent validity \\
\hline $\mathbf{X}_{\mathbf{2 3}} * \mathbf{X}_{\mathbf{1 4}}$ & -0.194 & 0.014 & -0.013 & 0.894 & 0.093 & $<0.001$ & Memenuhi convergent validity \\
\hline
\end{tabular}
Sumber: Data primer (diolah WarphPLS Ver 5.0, 2019)

Hasil pada tabel diatas, menunjukkan hasil pengujian Convergent validity untuk model 2, dimana pada model 1 sebelumnya terdapat beberapa indikator pada variabel Kepemimpinan, Disiplin kerja dan Produktivitas Karyawan yang tidak memenuhi standar Convergent validity sehingga dilakukan pengujian model 2. Pada pengujian model 2 diatas, semua indikator yang tidak memenuhi standar Convergent validity telah dikeluarkan dari model, sehingga pengujian Convergent validity pada model 2 telah memenuhi standar Convergent Validity dengan nilai >0.70 dan P-value juga telah memenuhi syarat yaitu memiliki nilai sebesar $<0,001(<0,05)$ untuk seluruh indikator dari variabel Kepemimpinan, Disiplin Kerja dan Produktivitas Karyawan.

\section{b. Uji Composite reliability (uji reliabilitas kontruks)}

Penelitian ini menggunakan tiga variabel laten (variabel yang tidak terukur) yaitu variabel Kepemimpinan (X) dan Disiplin Kerja (M) serta Produktivitas Karyawan (Y). Suatu variabel yang dipandang mampu (handal) dalam menjelaskan data dari variabel tersebut, pengujiannya dapat dilihat pada nilai composite reliability dan Cronbach's Alpha > 0,60, untuk itu dapat diperlihatkan pada tabel berikut:

Tabel 4.5

Latent variable coefficients (composite reliability) (model 1)

\begin{tabular}{ccrrr}
\hline MODEL 1 & KP & DSP & KNR & \multicolumn{1}{c}{ DSP*KP } \\
\hline R-Squared & & & 0.492 & \\
Composite reliab. & 0.823 & 0.803 & 0.916 & 0.86 \\
Cronbach's Alpha & 0.705 & 0.658 & 0.877 & 0.841 \\
Avg. Var. Extrac. & 0.558 & 0.56 & 0.733 & 0.351 \\
Full Collin. VIF & 1.096 & 1.647 & 1.915 & 2.115 \\
\hline
\end{tabular}




\begin{tabular}{cc}
\hline$Q$-Squared & 0.565 \\
\hline Sumber: Data primer (diolah WarphPLS Ver 5.0, 2019) &
\end{tabular}

Nilai composite reliability untuk variabel kepemimpinan sebesar 0,823>0,60 sedangkan untuk variabel disiplin kerja sebesar 0,803>0,60 dan pada variabel Produktivitas karyawan sebesar 0,916>0,60. Dan Sedangkan Varabel Kepemimpinan dimoderasi Disiplin Kerjasebesar 0,86 > 0,60 Selanjutnya untuk Cronbach's Alpha pada variabel Kepemimpinan sebesar 0,705>0,60 sedangkan untuk variabel disiplin kerja sebesar 0,658 > 0,60 dan pada variabel Kinerja Karyawan sebesar 0,877 > 0,60 dan terakhir variable kepemimpinan domoderasi disiplin kerja sebesar 0,841. Untuk nilai Average Variances Extracted (AVE)/ nilai variasi rata-rata pada variabel kepemimpinan sebesar 0,588 > 0,50 sedangkan untuk variabel disiplin kerja sebesar 0,56>0,50 dan pada variabel Produktivitas karyawan sebesar 0,733>0,50 dan terakhir pada variable kepemimpinan dimoderasi disiplin kerja sebesar $0,351<0,50$.

Tabel 4.6

Hasil output latent variable coefficients (model 2)

\begin{tabular}{ccrrr}
\hline MODEL 2 & KP & DSP & KNR & DSP*KP \\
\hline R-Squared & & & 0.556 & \\
Composite reliab. & 0.884 & 0.895 & 0.916 & 0.931 \\
Cronbach's Alpha & 0.803 & 0.819 & 0.877 & 0.914 \\
Avg. Var. Extrac. & 0.719 & 0.744 & 0.733 & 0.608 \\
Full Collin. VIF & 1.082 & 1.592 & 2.034 & 2.133 \\
Q-Squared & & & 0.602 & \\
\hline
\end{tabular}

Sumber: Data primer (diolah WarphPLS Ver 5.0, 2019)

Nilai composite reliability untuk variabel kepemimpinan sebesar 0,884 0,60 sedangkan untuk variabel disiplin kerja sebesar 0,895>0,60 dan pada variabel produktivitas karyawan sebesar 0,916>0,60 dan yang terakhir variable kepemimpinan dimoderasi disiplin kerja nilainya sebesar 0,931 > 0,60. Selanjutnya untuk cronbach's alpha pada variabel kepemimpinan sebesar 0,803>0,60 sedangkan untuk variabel disiplin kerja sebesar 0,819>0,60 dan pada variabel produktivitas karyawan sebesar 0,877 > 0,60 dan yang terakhir pada variable kepemimpinan dimoderasi disiplin kerja sebesar 0,914 >0,60. untuk nilai average variances extracted (ave)/ nilai variasi rata- 


\section{0 | Edy Jumady, PeRAN MOderasi DISIPLIN KERJA PADA PENGARUH KEPEMIMPINAN.}

rata pada variabel kepemimpinan sebesar 0,719>0,50 sedangkan untuk variabel disiplin kerja informasi sebesar 0,744 > 0,50 dan pada variabel produktivitas karyawan sebesar 0,733>0,50 dan terakhir pada variable kepemimpinan dimoderasi disiplin kerja sebesar $0,608>0,50$.

\section{c. Discriminant Validity (Validitas Diskriminan)}

Discriminant validity dinilai dari cross loading pengukuran dengan konstruk. Dapat dilihat dengan melihat loading konstruk laten, yang akan memprediksi indikatornya lebih baik daripada konstruk lainnya. Jika korelasi konstruk dengan pokok pengukuran (setiap indikator) lebih besar daripada ukuran konstruk lainnya maka validitas diskriminan terpenuhi.

Tabel 4.7

Nilai loading konstruk laten indikator ke konstruk lainnya

\begin{tabular}{|c|c|c|c|c|c|c|}
\hline \multirow{2}{*}{ Indikator } & \multirow{2}{*}{ Loading } & \multicolumn{4}{|c|}{ Nilai Loading ke konstruk lainnya } & \multirow[t]{2}{*}{ Keterangan } \\
\hline & & $\mathbf{K P}$ & DSK & KNK & DSK*KP & \\
\hline $\mathbf{X}_{12}$ & $\left.0.841\right|^{>}$ & & -0.141 & -0.031 & 0.018 & Memenuhi Discriminant validity \\
\hline $\mathbf{X}_{13}$ & $0.9>$ & & 0.028 & 0.111 & 0.08 & Memenuhi Discriminant validity \\
\hline $\mathbf{X}_{14}$ & $0.8>$ & & 0.116 & -0.092 & -0.109 & Memenuhi Discriminant validity \\
\hline $\mathbf{X}_{21}$ & $0.698>$ & -0.072 & & -0.437 & 0.272 & Memenuhi Discriminant validity \\
\hline $\mathbf{X}_{22}$ & $0.962>$ & -0.005 & & 0.072 & -0.06 & Memenuhi Discriminant validity \\
\hline $\mathbf{X}_{23}$ & $\left.0.905\right|^{>}$ & 0.061 & & 0.261 & -0.146 & Memenuhi Discriminant validity \\
\hline$Y_{11}$ & $0.911>$ & 0.087 & 0.021 & & 0.115 & Memenuhi Discriminant validity \\
\hline$Y_{12}$ & $\left.0.865\right|^{>}$ & -0.105 & 0.093 & & -0.113 & Memenuhi Discriminant validity \\
\hline$Y_{13}$ & $0.776>$ & 0.072 & 0.086 & & 0.057 & Memenuhi Discriminant validity \\
\hline$Y_{14}$ & $0.866>>$ & -0.05 & -0.192 & & -0.058 & Memenuhi Discriminant validity \\
\hline $\mathbf{X}_{21} * \mathbf{X}_{12}$ & $0.678>$ & -0.323 & 0.108 & -0.389 & & Memenuhi Discriminant validity \\
\hline $\mathbf{X}_{21} * \mathbf{X}_{13}$ & $0.462>$ & -0.167 & 0.043 & -0.763 & & Memenuhi Discriminant validity \\
\hline $\mathbf{X}_{21} * \mathbf{X}_{14}$ & $0.806>$ & -0.108 & 0.169 & -0.216 & & Memenuhi Discriminant validity \\
\hline $\mathbf{X}_{22} * \mathbf{X}_{12}$ & $0.862>$ & 0.017 & 0.081 & 0.406 & & Memenuhi Discriminant validity \\
\hline $\mathbf{X}_{22} * \mathbf{X}_{13}$ & $0.759>$ & 0.356 & -0.238 & -0.045 & & Memenuhi Discriminant validity \\
\hline $\mathbf{X}_{22} * \mathbf{X}_{14}$ & $0.914>$ & -0.14 & 0.067 & 0.069 & & Memenuhi Discriminant validity \\
\hline $\mathbf{X}_{23} * \mathbf{X}_{12}$ & $0.856>$ & 0.152 & -0.018 & 0.478 & & Memenuhi Discriminant validity \\
\hline $\mathbf{X}_{23} * \mathbf{X}_{13}$ & $0.678>$ & 0.398 & -0.26 & 0.021 & & Memenuhi Discriminant validity \\
\hline$X_{23} * X_{14}$ & $0.894 \mid>$ & -0.194 & 0.014 & -0.013 & & Memenuhi Discriminant validity \\
\hline
\end{tabular}

Sumber: Data primer (diolah WarphPLS Ver 5.0, 2019) 
Berdasarkan data di atas, keseluruhan indikator telah memenuhi kriteria validitas diskriminan. Variabel Kepemimpinan yang memiliki 3 indikator yang dilambangkan dengan $\mathrm{X}_{12}, \mathrm{X}_{13}$ dan $\mathrm{X}_{14}$. Untuk indikator $\mathrm{X}_{12}$ memiliki nilai loading 0,841 yang nilai loading-nya lebih besar dari loading ke konstruk lain yaitu -0,141 dan -0,031 dan ke 3 indikator karakteristik lainnya juga memiliki nilai loading yang lebih besar dari nilai loading ke konstruk lain.

Variabel disiplin kerja yang memiliki 3 indikator yang dilambangkan dengan $X_{21}$, $\mathrm{X}_{22}$ dan $\mathrm{X}_{23}$. Untuk indikator $\mathrm{X}_{21}$ memiliki nilai loading 0,698 yang nilai loading-nya lebih besar dari loading ke konstruk lain yaitu -0,072 dan -0,437 dan ke 2 indikator Disiplin Kerja lainnya juga memiliki nilai loading yang lebih besar dari nilai loading ke konstruk lain

Variabel produktivitas karyawan memiliki 4 indikator yang dilambangkan dengan $\mathrm{Y}_{11}, \mathrm{Y}_{12}, \mathrm{Y}_{13}$ dan $\mathrm{Y}_{14}$. Untuk indikator $\mathrm{Y}_{11}$ memiliki nilai loading 0,911 yang nilai loading-nya lebih besar dari loading ke konstruk lain yaitu 0,087 dan 0,021 dan ke 3 Disiplin Kerja lainnya juga memiliki nilai loading yang lebih besar dari nilai loading ke konstruk lain. Berdasarkan uraian tersebut, dapat disimpulkan bahwa keseluruhan indikator telah memenuhi kriteria validitas diskriminan.

\section{1) Evaluasi Model Struktural (Inner Model)}

Pada uji kecocokan model terdapat 3 indeks pengujian, yaitu average path coefficient (APC), average Rsquared (ARS) dan average varians factor (AVIF) dengan kriteria APC dan ARS diterima dengan syarat $\mathrm{p}$ - value $<0,05$ dan AVIF $<5$ (Mahfud Sholihin dan Dwi Ratmono, 2013: 61). Berikut ini adalah hasil output model fit indices yang disajikan dalam bentuk tabel yaitu:

Tabel 4.8

Hasil output model fit indices

\begin{tabular}{lrlll}
\hline & Indeks & $P$-Value & Kriteria & Keterangan \\
\hline Average path coefficient (APC) & 0.344 & $\mathrm{P}<0.001$ & $\mathrm{P}<0.05$ & Diterima \\
Average R-squared (ARS) & 0.578 & $\mathrm{P}<0.001$ & $\mathrm{P}<0.05$ & Diterima \\
Average block VIF (AVIF) & 1.409 & & AVIF $<5$ & Diterima \\
\hline
\end{tabular}

Sumber: Data primer (diolah WarphPLS Ver 5.0, 2019) 


\section{2 | Edy Jumady, PERAN MODERASI DISIPLIN KERJA PADA PENGARUH KEPEMIMPINAN.}

Hasil output di atas, menjelaskan bahwa APC memiliki indeks sebesar 0,344 dengan nilai $\mathrm{p}$ - value $<0,001$. Sedangkan ARS memiliki indeks sebesar 0,578 dengan $\mathrm{p}$ - value $<0,001$. Berdasarkan kriteria, APC sudah memenuhi kriteria karena memiliki nilai $\mathrm{p}<0,001$. Begitu pula dengan nilai $\mathrm{p}$ dari ARS yaitu $\mathrm{p}<0,001$. Nilai AVIF yang harus $<5$ sudah terpenuhi karena berdasarkan data tersebut AVIF nilainya 1,409. Dengan demikian, maka inner model dapat diterima.

\section{a. Hasil Uji Hipotesis}

Tabel 4.9

Direct Effects

\begin{tabular}{|l|l|l|l|l|l|}
\hline Kriteria & Variabel & KP & DSK & KNR & DSK*KP \\
\hline Path coefficients & KP & - & - & - & - \\
\cline { 2 - 6 } & DSK & - & - & - & - \\
\cline { 2 - 6 } & KNR & -0.228 & 0.265 & - & 0.539 \\
\cline { 2 - 6 } & DSK*KP & - & - & - & - \\
\hline \multirow{4}{*}{-values } & KP & - & - & - & - \\
\cline { 2 - 6 } & DSK & - & - & - & - \\
\cline { 2 - 6 } & KNR & 0.029 & 0.013 & - & $<0.001$ \\
\cline { 2 - 6 } & DSK*KP & - & - & - & - \\
\hline \multirow{3}{*}{$\begin{array}{l}\text { patfect size for } \\
\text { Kath }\end{array}$} & KP & - & - & - & - \\
\cline { 2 - 6 } & DSK & - & - & - & - \\
\cline { 2 - 6 } & KNR & 0.051 & 0.144 & - & 0.382 \\
\cline { 2 - 6 } & DSK*KP & - & - & - & - \\
\hline
\end{tabular}

Sumber: Data primer (diolah WarphPLS Ver 5.0, 2019)

Hasil output di atas, menjelaskan bahwa path coefficients untuk variabel kepemimpinan terhadap produktivitas karyawan memiliki indeks sebesar -0,228 dengan nilai $p$ - value 0,029 dan nilai effect size for path 0,051 sedangkan untuk path coefficients variabel disiplin kerja terhadap Produktivitas Karyawan memiliki indeks sebesar 0,265 dengan $p$-value 0,013 nilai effect size for path 0,144 sedangkan untuk variabel kepemimpinan terhadap produktivitas karyawan dimoderasi Disiplin Kerja memiliki indeks sebesar 0,539 dengan nilai $p$-value $<0,001$ nilai effect size for path 0,382. Berikut ini merupakan gambar hasil penelitian dari effect size yang telah diperoleh berdasarkan pengolahan data: 


\section{Gambar 4.1}

Hasil penelitian

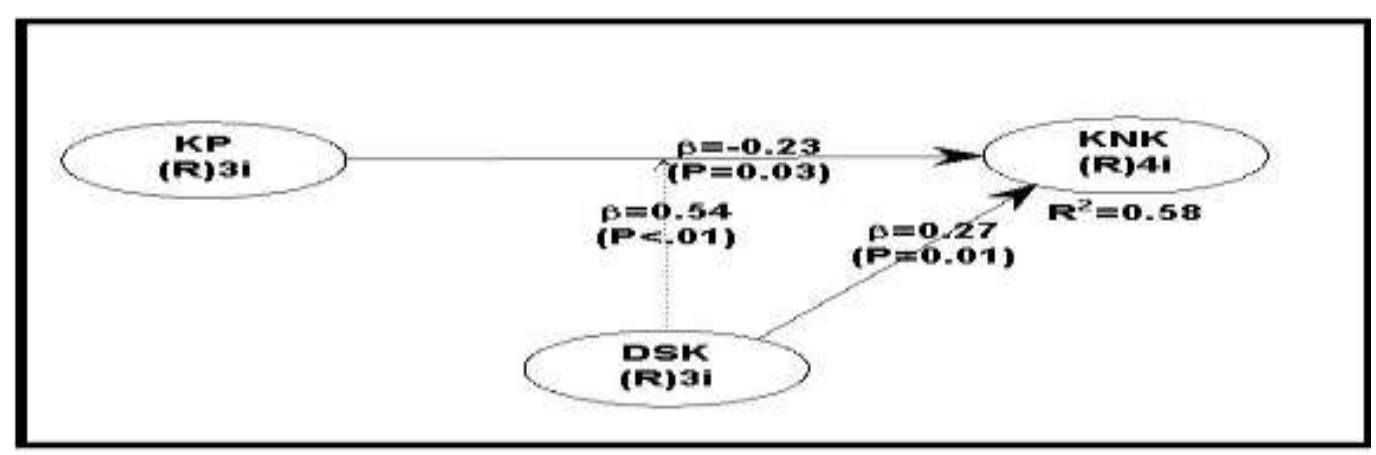

Sumber: Data primer (diolah WarphPLS Ver 5.0, 2019)

(Angka merupakan pembulatan dari path coefficients dan $p$-values pada tabel 4.)

Keterangan : $\quad$ KP : Kepemimpinan

DSK : Disiplin Kerja

KNR : Produktivitas Kerja Karyawan

Berikut ini, pengujian hipotesis yang diuraikan lebih lanjut sebagai berikut:

1. Uji Hipotesis 1

Kepemimpinan berpengaruh negative dan signifikan terhadap produktivitas karyawan pada pada perbankan syariah di Makassar. Dimana $p$-value $=0,029(\leq 0,05)$ namun Koefisien jalur bertanda negative $\mathrm{m}$ maka $\mathrm{H}_{1}$ ditolak

Variabel Disiplin Kerja berpengaruh negatif dan Signifikan terhadap Produktivitas Karyawan pada perbankan syariah di Makassar. Hal tersebut menunjukkan bahwa variabel Kepemimpinan yang ditunjukkan kepada Manager kepada bawahan tergolong rendah maneger kurang mampu mengayomi bawahan namaun dalam pelaksanaannya terbukti mampu meningkatkan produktivitas karyawan.

2. Uji Hipotesis 2

Disiplin Kerja berpengaruh Positive dan signifikan terhadap Kinerja Karyawan pada pada perbankan syariah di Makassar. Dimana $p$-value $=0,014(<0,05)$ maka $_{2}$ diterima.

Disiplin Kerja berpengaruh terhadap produktivitas karyawan pada perbankan syariah di Makassar. Hal tersebut menunjukkan bahwa variabel disiplin kerja memiliki pengaruh terhadap kinerja karyawan yang dapat diamati melalui nilai koefisien jalur 


\section{4 | Edy Jumady, Peran mOderasi disiplin KeRJA PADA PENGARUH KEPEMIMPINAN.}

yaitu 0,265. Angka ini menunjukkan bahwa jika terjadi peningkatan pada disiplin kerja maka produktivitas karyawan akan meningkat sebesar 0,265 dan begitu pula sebaliknya, setiap terjadi penurunan disiplin kerja, maka produktivitas karyawan akan menurun sebesar 0,265 .

\section{Uji Hipotesis 3}

Kepemimpinan berpengaruh Positive dan signifikan terhadap Produktivitas Karyawan dimoderasi Disiplin Kerja pada perbankan syariah di Makassar. Dimana $p$ value $=<0,001(\leq 0,05)$ maka $\mathrm{H}_{3}$ diterima.

Kepemimpinan berpengaruh terhadap produktivitas karyawan dimoderasi disiplin kerja pada perbankan syariah di Makassar. Hal tersebut menunjukkan bahwa variabel disiplin kerja mampu memperkauat variable kepemimpinan terhadap produktivitas Karyawan yang dapat diamati melalui nilai koefisien jalur yaitu 0.539. Angka ini menunjukkan bahwa jika nilai koefisien jalur variabel disiplin kerja mampu memperkuat variable kepemimpinan terhadap disiplin kerja.

Setelah melakukan uji hipotesis di atas, berikut ini tabel yang merangkum uji hipotesis-hipotesis tersebut :

\section{Tabel 4.10}

Hasil uji hipotesis

\begin{tabular}{|c|c|c|c|c|c|}
\hline Hipotesis & Independen & Dependen & beta $(\beta)$ & $p$-values & Keputusan \\
\hline $\mathrm{H}_{1}$ & $\begin{array}{l}\text { Produktivitas Kerja } \\
\text { Karyawan }\end{array}$ & Kepemimpinan & -0.228 & 0.029 & $\begin{array}{l}\text { Ditolak } \\
\text { sebagian }\end{array}$ \\
\hline $\mathrm{H}_{2}$ & $\begin{array}{l}\text { Produktivitas Kerja } \\
\text { Karyawan }\end{array}$ & Disiplin Kerja & 0.265 & 0.013 & Diterima \\
\hline $\mathrm{H}_{3}$ & $\begin{array}{l}\text { Produktivitas Kerja } \\
\text { Karyawan }\end{array}$ & $\begin{array}{l}\text { Kepemimpinan } \\
\text { dimoderasi } \\
\text { Disiplin kerja }\end{array}$ & 0.539 & $<0.001$ & Diterima \\
\hline
\end{tabular}

Sumber: Data primer (diolah WarphPLS Ver 5.0, 2019)

1. Uji hipotesis 1 ditolak sebagian, artinya variabel kepemimpinan memiliki pengaruh negatif dan signifikan terhadap produktivitas karyawan pada perbankan syariah di Makassar. Hal ini ditunjukkan dengan nilai beta $(\beta)$ sebesar $-0,228$ dengan nilai $p$ value 0,029 .

2. Uji hipotesis 2 diterima, artinya variabel disiplin kerja memiliki pengaruh positif dan signifikan terhadap produktivitas karyawan pada perbankan syariah di 
Makassar. Hal ini ditunjukkan dengan nilai beta $(\beta)$ sebesar 0,265 dengan nilai $p$ value 0,013 .

3. Uji hipotesis 3 diterima, artinya variabel disiplin kerja dapat memperkuat variable kepemimpinan terhadap produktivitas Karyawan pada perbankan syariah di Makassar. Hal ini ditunjukkan dengan nilai beta $(\beta)$ sebesar 0,539 dengan nilai $p$ value $<0,001$.

\section{b. Uji besaran pengaruh variabel independen terhadap variabel dependen}

Pengujian besaran pengaruh variabel independen terhadap variabel dependen dapat ditunjukkan pada tabel berikut :

Tabel 4.11

Ringkasan model (model summary)

\begin{tabular}{lcrrr}
\hline \multicolumn{1}{c}{ Pengukuran } & KP & DSK & KNR & DSK*KP \\
\hline R-squared & & & 0.578 & \\
Adj. - -squared & & & 0.556 & \\
Composite reliab. & 0.884 & 0.895 & 0.916 & 0.931 \\
Cronbach's Alpha & 0.803 & 0.819 & 0.877 & 0.914 \\
Avg. Var. Extrac. & 0.719 & 0.744 & 0.733 & 0.608 \\
\hline Sumber: & & & &
\end{tabular}

Sumber: Data primer (diolah WarphPLS Ver 5.0, 2019)

Berdasarkan tabel diatas besaran pengaruh nilai $R$-squared pada variabel Kepemimpinan dan variabel Disiplin Kerja terhadap produktivitas Karyawan adalah $0,587(58,7 \%)$ dan sisanya $41,3 \%$ dipengaruhi oleh variabel lain yang tidak dianalisis dalam penelitian ini seperti motivasi kerja, lingkungan kerja, dan variabel lainnya.

Penelitian ini membahas pengaruh kepemimpinan terhadap produktivitas karyawan, pengaruh disiplin kerja terhadap kinerja karyawan dan pengaruh kepemimpinan terhadap produktivitas karyawan dimoderasi disiplin Kerja pada perbankan syariah di Makassar.

\section{c. Pengaruh Kepemimpinan Terhadap Produktivitas Karyawan}

Berdasarkan hasil penelitian, ditemukan bahwa kepemimpinan berpengaruh negative dan signifikan terhadap produktivitas karyawan. Hasil ini dibantah sebagian dengan teori atau temuan dalam penelitian sebelumnya oleh (Posuma, 2013) dan 


\section{6 | Edy Jumady, PERAN MOderASI DISIPLIN KERJA PADA PENGARUH KEPEMIMPINAN..................}

penelitian (D. S. Widodo, 2014) memberikan bukti bahwa kepemimpinan berpengaruh negative dan tidak signifikan terhadap produktivitas karyawan.

Dalam penelitian ini dapat dilihat dari nilai koefisien beta $(\beta)$ sebesar -0.228 yang menunjukkan bahwa kepemimpinan pada perbankan syariah di Makassar belum mampu mengayomi bawahan namun terbukti nyata mampu meningkat produktivitas karyawan kondisi tersebut diakibatkan karna pelaksanaan tugas yang diberikan manager kepada bawahan tidak selesaikan dengan baik sehingga berdampak pada rendahnya pekerjaan yang diselesaikan.

\section{d. Pengaruh Disiplin Kerja Terhadap Produktivitas Karyawan}

Berdasarkan hasil penelitian, ditemukan bahwa disiplin kerja memiliki pengaruh terhadap produktivitas karyawan. Hasil ini sama dengan teori atau temuan dalam penelitian sebelumnya oleh (Prawatya \& Raharjo, 2012) bahwa disiplin kerja berpengaruh positif dan signifikan terhadap kinerja karyawan.

Dalam penelitian ini dapat dilihat dari nilai koefisien beta yang menunjukkan bahwa disiplin kerja memiliki pengaruh positif dan signifikan terhadap produktivitas karyawan yaitu dengan nilai beta $(\beta)$ sebesar 0,265 . Hal ini menunjukkan bahwa variabel disiplin kerja mampu memengaruhi peningkatan produktivitas karyawan. Penyebab positif dan signifikannya pengaruh disiplin kerja terhadap kinerja karyawan diakibatkan karena karyawan mampu menyelesaikan pekerjaan dengan teliti diakibatkan karena adanya kepatuhan karyawan dalam menyelesiakan pekerjaan sesuai dengan standar perusahaan.

Kondisi tersebut didukung dengan karyawan yang mampu menyelesaikan tuntutan pekerjaan dengan cepat dan sesuai dengan yang ditetapkan perusahaan sehingga berdampak pada karyawan dapat terhindar dari sanksi dalam perusahaan.

\section{e. Pengaruh Kepemimpinan Terhadap Produktivitas Karyawan dimoderasi Disiplin Kerja}

Berdasarkan hasil penelitian, ditemukan bahwa kepemimpinan bengaruh positive signifikan terhadap produktivitas karyawan dimoderasi disiplin kerja. Hasil tersebut 
dalam penelitian ini dapat dilihat dari nilai koefisien beta yang ditunjukkan karakteristik lebih tinggi yaitu dengan nilai beta $(\beta)$ sebesar 0,539 .

Hal ini menunjukkan bahwa variabel disiplin kerja dapat memperkuat nilai pada variable kepemimpinan terhadap produktivitas karyawan. Penyebab positif dan signifikannya disebabkan karna adanya karyawan yang patuh terhadap tugas yang diberikan oleh manager selain itu manager mengeluarkan seluruh kemampuan dalam setiap tugas yang diberikan kepada karyawan.

Kondisi tersebut berberda dengan fakta lapang yang dimana para karyawan patuh terhadap tugas yang diberikan dan karyawan yang ada diperusahaan tersebut dating tidak tepat pada waktunya pulang cepat dan menggunakan waktu instirahat mereka tidak sesuai dengan ketentuan didalam perusahaan. Selain dari para karyawan, para maneger disana tidak mampu mengarahkan bawahan apa yang harus dikerjakan dan para maneger tidak selalu berfikir pada prestasi perusahaan, para manager kurang berpartisipasi dengan anggotanya.

\section{Simpulan}

Berdasarkan hasil pengujian dan pembahasan sebagaimana telah disajikan, maka dapat ditarik kesimpulan sebagai berikut:

1. Kepemimpinan berpengaruh negative dan signifikan terhadap produktivitas karyawan. Koefisien bertandah negative dan signifikannya pengaruh kepemimpinan terhadap produktivitas karyawan diakibatkan karena para manager berlum mampu mengayomi bawahan namun terbukti nyata mampu meningkatkan kinerja karyawan kondisi tersebut diakibatkan karena pelaksanaan tugas yang diberikan manager kepada bawahan, dan tidak diselesaikan dengan baik sehingga rendahnya pekerjaan yang diselesaikan.

2. Disiplin kerja berpengaruh positive dan signifikan terhadap produktivitas karyawan. koefisian bertanda positive dan signifikan terhadap produktivitas karyawan dikarenakan karyawan mampu menyelesaikan pekerjaan dengan teliti diakibatkan karena adanya kepatuhan karyawan dalam menyelesaikan pekerjaan sesuai dengan standar perusahaan. Kondisi tersebut didukung dengan karyawan 
18 Edy Jumady, PERAN MODERASI DISIPLIN KERJA PADA PENGARUH KEPEMIMPINAN.

yang mampu menyelesaikan tuntutan pekerjaan dengan cepat dan sesuai dengan yang ditetapkan perusahaan sehingga berdampak pada karyawan dapat terhindar dari sanksi dalam perusahaan.

3. Disiplin kerja dapat memperkuat kepemimpinan terhadap produktivitas karyawan. Penyebab positif dan signifikan disebabkan karena adanya karyawan yang patuh terhadap tugas yang diberikan oleh manager selain itu manager mengeluarkan seluruh kemampuan dalam setiap tugas yang diberikan kepada karyawan.

\section{DAFTAR PUSTAKA}

Abdillah, A. C., \& Wajdi, F. (2011). Pengaruh Kepemimpinan, Stres Kerja, Disiplin Kerja, dan Kompensasi Dengan Kinerja Pegawai. Ekonomi Manajemen Sumber Daya, 12(1), 1-11.

Erisna, N. (2012). Hubungan Disiplin Dan Motivasi Kerja Dengan Kinerja Pegawai Pada Dinas Pendidikan Kabupaten Way Kanan. Jurnal Manajemen Dan Bisnis, 2(2), 167-180.

Ghozali, I. (2013). Aplikasi Analisis Multivariat dengan Program IBM SPSS. (Edisi 7). Semarang: Penerbit Universitas Diponegoro.

Https://makassar.tribunnews.com/2019/04/30/pembiayaan-bank-syariah-di-sulseltumbuh-namun-turun.

Luthans, F. (2011). Perilaku Organisasi. Yogyakarta: Penerbit Andi.

Mondiani, T. (2012). Pengaruh Kepemimpinan Transformasional Dan Kompensasi Terhadap Kinerja Karyawan Pt. Pln (Persero) Upj Semarang. Jurnal Administrasi Bisnis Undip, 1(1), 46-54.

Nitisemito, A. S. (2014). Manajemen Personalia, Ghalia Indonesia. Jakarta: Penerbit Ghalia Indonesia.

P. Siagian, S. (2002). Kepemimpinan Organisasi \& Perilaku Administrasi. Jakarta: Penerbit Gunung Agung.

Posuma, C. (2013). Kompetensi, Kompensasi, Dan Kepemimpinan Pengaruhnya Terhadap Kinerja Karyawan Pada Rumah Sakit Ratumbuysang Manado. Jurnal Riset Ekonomi, Manajemen, Bisnis Dan Akuntansi, 1(4), 646-656.

Prawatya, D. A., \& Raharjo, S. T. (2012). Terhadap Kinerja Karyawan Pabrik Minyak Kayu Putih ( PMKP ) DI KRAI PURWODADI, 1, 1-9. 
Riyadi, S. (2011). Pengaruh Kompensasi Finansial, Gaya Kepemimpinan, dan Motivasi Kerja Terhadap Kinerja Karyawan pada Perusahaan Manufaktur di Jawa Timur. Jurnal Manajemen Dan Kewirausahaan, 13(1), 40-45.

Sedarmayanti. (2009). Sumber Daya Manusia dan Produktivitas Kerja. Bandung: Penerbit Mandar Maju.

Susanty, A., \& Baskoro, S. W. (2016). Pengaruh Motivasi Kerja Dan Gaya Kepemimpinan Terhadap Disiplin Kerja Serta Dampaknya Pada Kinerja Karyawan (Studi Kasus Pada Pt. Pln (Persero) Apd Semarang). J@Ti Undip : Jurnal Teknik Industri, 7(2), 77-84. https://doi.org/10.12777/jati.7.2.77-84

Widodo, D. S. (2014). Influence of Leadership And Work Environment To Job Satisfaction And Impact To Employee Performance (Study On Industrial Manufacture In West Java). Journal of Economics and Sustainable Development, 5(26), 62-66.

Widodo, T. (2010). Pengaruh Lingkungan Kerja, Budaya Organisasi, Kepemimpinan Terhadap Kinerja (Studi pada Pegawai Kecamatan Sidorejo Kota Salatiga). Jurnal Among Makarti, 3(5), 14-35

Zamzam, Fakhry, Havis Aravik, (2016). Manajemen SDM Berbasis Syariah, Bogor: CV. RWTC Success.. 
20 | Edy Jumady, PERAN MOderasi DISIPLIN KERJA PADA PENGARUH KEPEMIMPINAN.................. 